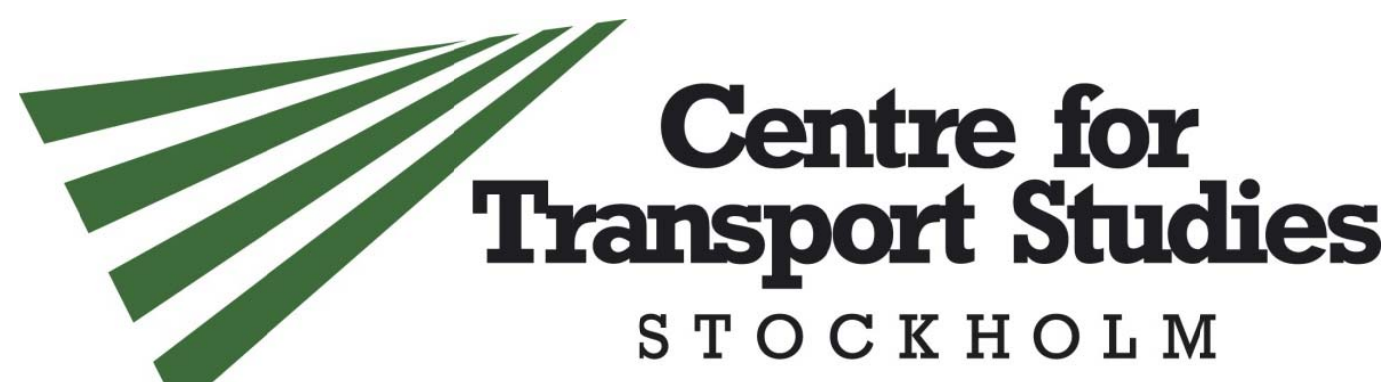

Can high speed rail offset its embedded emissions?

Jonas Westin - KTH

Per Kågeson - KTH

CTS Working Paper 2011: 16

\begin{abstract}
The purpose of this paper is to analyze the climate benefit of investments in high speed rail-way lines given uncertainty in future transport demand, technology and power production. To capture the uncertainty of estimated parameters, distributions for the annual traffic emissions reduction required to compensate for the embedded emissions from the construction of infrastructure are calculated using Monte Carlo simulation. In order to balance the annualized emissions from the railway construction, traffic volumes of more than 10 million annual one-way trips are usually required. Most of the traffic diverted from other modes must come from aviation and the project cannot involve the extensive use of tunnels. In sparsely populated regions it may be, from a climate point of view, better to upgrade existing lines and to try to make people substitute air travel by modern telecommunications, rather than investing large amounts of resources in enabling people to travel faster and more often.
\end{abstract}

Keywords: High-speed Rail, CO2 emissions, Embedded emissions, Infrastructure investment, Monte Carlo simulation, Sensitivity analysis

JEL Codes: R42, Q54

Centre for Transport Studies

SE-100 44 Stockholm

Sweden

www.cts.kth.se
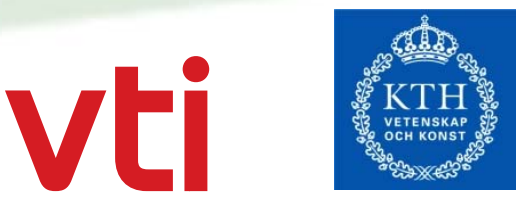



\title{
Can high speed rail offset its embedded emissions?
}

\author{
Jonas Westin ${ }^{\mathrm{a}, \mathrm{b}}$ \\ Per Kågeson ${ }^{\mathrm{a}}$
}

\begin{abstract}
The purpose of this paper is to analyze the climate benefit of investments in high speed railway lines given uncertainty in future transport demand, technology and power production. To capture the uncertainty of estimated parameters, distributions for the annual traffic emissions reduction required to compensate for the embedded emissions from the construction of infrastructure are calculated using Monte Carlo simulation. In order to balance the annualized emissions from the railway construction, traffic volumes of more than 10 million annual oneway trips are usually required. Most of the traffic diverted from other modes must come from aviation and the project cannot involve the extensive use of tunnels. In sparsely populated regions it may be, from a climate point of view, better to upgrade existing lines and to try to make people substitute air travel by modern telecommunications, rather than investing large amounts of resources in enabling people to travel faster and more often.
\end{abstract}

Keywords: High-speed Rail, CO2 emissions, Embedded emissions, Infrastructure investment, Monte Carlo simulation, Sensitivity analysis

Preprint submitted to Elsevier

Westin, J., Kågeson, P., 2012. Can high speed rail offset its embedded emissions?

Transportation Research Part D: Transport and Environment 17(1), 1-7,

doi:10.1016/j.trd.2011.09.006.

\footnotetext{
${ }^{a}$ Centre for Transport Studies, KTH Royal Institute of Technology, SE-100 44 Stockholm, Sweden

${ }^{\mathrm{b}}$ Department of Transport Science, KTH Royal Institute of Technology, SE-100 44 Stockholm, Sweden
} 


\section{Introduction}

Although high speed in all modes of transport comes at the price of negative environmental impact, many environmentalists, and the companies and interest organizations of the rail sector, claim that high speed rail is environmentally beneficial and should be allowed to form an important part of climate change mitigation (Swedish Rail Administration, 2008, UIC, 2008, UNIFE, 2008). Independent research, on the other hand, concludes that these benefits may not be that large (de Rus and Nash, 2007, de Rus, 2008, Kågeson, 2009, Nilsson and Pydokke, 2009).

The embedded $\mathrm{CO}_{2}$ emissions from constructing and maintaining a high speed link is often large, partly because of the extensive use of steel and concrete, which are highly energy intensive in their production (Network Rail, 2009). For a new investment in high speed rail to make sense from a climate perspective, these embedded emissions must be offset by the reduction in greenhouse gases that is the result of traffic shifting from high-emitting modes to rail when the new link is opened.

The aim of this paper is to determine the amount of annual passenger trips and the magnitude of shift from other modes that are required for compensating for the embedded emissions from the construction of a reference high speed rail project, when depreciated over the lifetime of the infrastructure. Since the expected lifetime of the components in the railway differs, the embedded emissions are calculated using a steady-state approach where all components are assumed to be continuously replaced and recycled at the end of their lifetime.

The objective of the UNFCCC's climate change policy is to prevent greenhouse gases from exceeding a concentration in the atmosphere that would raise the global mean temperature by more than $2{ }^{\circ} \mathrm{C}$ above its pre-industrial level. As the atmosphere under current trends will approach this critical concentration of greenhouse gases within a few decades, the payback time for emissions caused in the near term by large projects must be sufficiently short to prevent them from contributing to an overdraft. We have therefore chosen to calculate the carbon annuity based on a 50 year analysis period starting in 2010. This affects the assumptions with regard to available technologies and energy use.

A potential side-effect of building a new line for high speed trains is that the capacity is increased for the movement of freight trains and regional or local passenger trains on the preexisting rail infrastructure. An indirect effect of this may be a growing shift from road to track that reduces the overall environmental impact of passenger and freight transport. However, for this to happen there must be a latent demand for transport by rail that could previously not be met for lack of capacity. This potential side-effect is disregarded in the following analysis.

\section{Methodology}

The size of the net carbon benefit from a future high-speed train link depends on a number of parameters, among them: the energy per seat kilometer needed for moving different vehicles; the carbon dioxide emitted from the combustion of fossil fuels used for vehicle propulsion; the origin of the electricity; the average rate of occupancy for different transport modes; and the division of generated traffic on diverted traffic from other modes of transport, generated new traffic and pre-existing train passengers. The future values of all these parameters are associated with uncertainty. 
In this paper a parametric model is used to calculate the change in $\mathrm{CO}_{2}$ emissions per passenger kilometer from a person shifting to high speed rail from another travel mode. The calculations are based on assumptions concerning the amount of energy per seat kilometer needed for moving different new vehicles/vessels in intercity traffic in 2025. These values are then translated into $\mathrm{CO}_{2}$ emissions using figures for the carbon content of different fuel types and assumptions regarding the average load factors for each vehicle type. To evaluate the total environmental effect of building a new high speed link, five scenarios are specified to capture different sources of the generated traffic.

To capture the uncertainty of the estimates, Monte Carlo simulation is used. Monte Carlo simulation is a method for transforming a deterministic model into a stochastic model. To capture uncertainties in the input parameters, a probability distribution over likely future values of each parameter is assigned. Using Monte Carlo simulation, the distribution of the net $\mathrm{CO}_{2}$ emissions are calculated. In the simulation, the change in emissions per passenger kilometer and the resulting net emissions for all five scenarios are calculated using random draws from the parameter distributions. The process is repeated 1,000,000 times until stable simulated distributions for the resulting net emissions are obtained for all transport modes.

To facilitate the specification of the model, all parameters are assumed to be triangle distributed. By using triangle distributions only a lowest, a highest and a central or most likely value for each parameter need to be specified. When creating the model, several correlation structures were tried, but the effects on the final results were found to be small. To simplify the model specification, all random parameters are therefore assumed to be independent.

\subsection{Parameters}

The sensitivity analysis clearly indicates that for most parameters the choice of value (within reasonable limits) does not significantly affect the depreciation of the embedded emissions. Therefore, the paper focus on the few parameters for which the choice of value is highly influential. These are: the marginal electricity production; the total radiative forcing factor of short-haul aircraft; and the assumed occupancy rate of the various vehicles and vessels. Assumptions on how generated traffic is divided on shifts from different modes and on new generated traffic are also important. The central values for all other parameters have been taken from Kågeson (2009). The highest and lowest values in the distributions have been selected as to provide estimates that significantly differ from the central value without being completely unrealistic. The distributions for all parameters are summarized in Table 1. 
Table 1: Parameter distributions for all model parameters

\begin{tabular}{|c|c|c|c|}
\hline $\begin{array}{l}\text { Parameter distribution for } \mathrm{CO}_{2} \text { emissions from marginal } \\
\text { electricity production }\end{array}$ & Low & Central & High \\
\hline Emission from marginal electricity production $\left(\mathrm{g} \mathrm{CO}_{2} / \mathrm{kWh}\right)$ & 225 & 530 & 700 \\
\hline Parameter distribution for $\mathrm{CO}_{2}$ emissions from aircrafts & Low & Central & High \\
\hline Energy requirement for short range aircrafts (kWh/seat km) & 0.216 & 0.245 & 0.274 \\
\hline $\begin{array}{l}\text { Emissions per seat kilometer (without forcing factor) for aircraft (g } \\
\mathrm{CO}_{2} / \text { seat km) }\end{array}$ & 55.4 & 63 & 70.6 \\
\hline Radiative forcing factor of short-haul aviation (factor of $\mathrm{CO}_{2}$ ) & 1.0 & 1.3 & 1.5 \\
\hline Parameter distribution for $\mathrm{CO}_{2}$ emissions from buses & Low & Central & High \\
\hline Energy requirement for long-distance buses (kWh/seat km) & 0.036 & 0.042 & 0.048 \\
\hline Emissions per seat kilometer for bus ( $\left.\mathrm{g} \mathrm{CO}_{2} / \mathrm{seat} \mathrm{km}\right)$ & 9.58 & 11.17 & 12.77 \\
\hline Parameter distribution for $\mathrm{CO}_{2}$ emissions from cars & Low & Central & High \\
\hline $\begin{array}{l}\text { Energy requirement for cars with internal combustion engines } \\
\text { (kWh/seat km) }\end{array}$ & 0.068 & 0.079 & 0.090 \\
\hline $\begin{array}{l}\text { Emissions per seat kilometer for car with internal combustion } \\
\left.\text { engine run on 50/50 diesel/gasoline ( } \mathrm{g} \mathrm{CO}_{2} / \text { seat } \mathrm{km}\right)\end{array}$ & 18 & 21 & 24 \\
\hline $\begin{array}{l}\text { Estimated average blend of biofuel in diesel and gasoline for car } \\
\text { (per cent) }\end{array}$ & 10 & 20 & 30 \\
\hline Climate efficiency biofuel reduction factor for car (per cent) & 55 & 65 & 75 \\
\hline Energy requirement for all electric cars (kWh/seat km) & 0.032 & 0.040 & 0.048 \\
\hline Share of intercity car traffic running on electricity (per cent) & 5 & 10 & 20 \\
\hline Parameter distribution for energy requirement of trains & Low & Central & High \\
\hline Energy requirement for high speed trains (kWh/seat km) & 0.026 & 0.029 & 0.033 \\
\hline Energy requirement for conventional trains (kWh/seat km) & 0.016 & 0.018 & 0.022 \\
\hline Parameter distribution for average load factors & Low & Central & High \\
\hline Short range aircrafts & 0.70 & 0.80 & 0.90 \\
\hline Long-distance buses & 0.40 & 0.55 & 0.70 \\
\hline Cars & 0.30 & 0.40 & 0.50 \\
\hline High speed trains & 0.65 & 0.75 & 0.85 \\
\hline Conventional trains & 0.55 & 0.65 & 0.75 \\
\hline
\end{tabular}

\subsection{1. $\mathrm{CO}_{2}$ emission from marginal electricity production}

On average, current European power plants emit between 410 and $443 \mathrm{~g}$ of $\mathrm{CO}_{2}$ per $\mathrm{kWh}$ produced (Hacker et al., 2009). More than 50 per cent of the power production in Europe is based on the combustion of fossil fuels. Even in Scandinavia where the average $\mathrm{CO}_{2}$ emissions from power production is less than $100 \mathrm{~g}$, the average effect on emissions from marginal demand is between 660 and $700 \mathrm{~g}$ of $\mathrm{CO}_{2}$ per $\mathrm{kWh}$ (Vessia and Byskov Lindberg, 2008, Sköldberg and Unger, 2008). All else equal, rising demand for electricity will make it more difficult to phase out all power plants that burn hard coal or lignite.

When investment in high speed rail results in modal shift and newly generated traffic - it is a matter of change. Under dynamic circumstances, average figures cannot be used for calculating the climate effect. Instead the marginal effect on emissions of greenhouse gases of rising demand for electricity is what matters. The marginal power production may differ somewhat over the months of the year as well as between day and night. The differences between national markets, however, are gradually diminishing as a result of the emerging common European electricity market and the improved transmission of electricity. According to ENTSOE (2010), European integration will require more than 35,000 km of new highvoltage transmission lines to be built before 2020 . 
Kampman et al. (2010) have analyzed the effect on the grids in Germany, France and the United Kingdom from a partial electrification of road transport. They conclude that increasing demand in Germany would result in more night-time use of lignite and hard coal and more day-time use of natural gas and/or lignite. France uses nuclear power and gas for balancing demand, while the UK relies heavily on gas for this purpose, which may partly be replaced by coal depending on future relative prices.

An effect of higher demand is that it will take longer to replace existing fossil-fueled power production with renewable sources or longer to equip them with CCS (Carbon Capture and Storage). France and Norway are examples of large net-exporters of carbon-free electricity. However, rising demand in such countries means that less capacity can be used for export purposes to replace lignite and hard coal in, for instance, Germany and Poland.

The European Environmental Agency (2009) expects the EU's RED-directive and a gradual lowering of the cap of the European Emission Trading Scheme (EU ETS) to result in emissions from European power production being reduced to on average $130 \mathrm{~g}$ of $\mathrm{CO}_{2}$ per kWh in 2030, whilst International Energy Agency (2009) presents a forecast of $312 \mathrm{~g}$ in the World Energy Outlook's reference scenario for 2030. Emissions from marginal production will, of course, be higher.

The estimated parameter distribution for the average $\mathrm{CO}_{2}$ emissions of marginal electricity production in Europe, during the entire depreciation period, is assumed to range from 100 to $700 \mathrm{~g} / \mathrm{kWh}$ with 400 as a central estimate. In the case when the marginal electricity production takes place in coal-fired condensing stations, which use carbon capture and storage, the emissions would be around $120 \mathrm{~g} / \mathrm{kWh}$ - as CCS is not able to capture more than 83-89\% of the emissions (Golombek et al, 2011). However, commercial application of CCS is not expected to happen until sometime after 2020, and will therefore affect the second half of the 50 year analysis period much more than the first.

\subsection{2. $\mathrm{CO}_{2}$ emission from short range aircrafts}

Assuming all planes run on kerosene, the estimated $\mathrm{CO}_{2}$ emissions from a short range aircraft can be calculated using the estimated energy requirement and the carbon content of the fuel. To take account of the fact that airplanes emit several other gases and substances that contribute to global warming, the estimated $\mathrm{CO}_{2}$ emissions per seat kilometer from the aircraft is multiplied by a radiative forcing factor to get a total estimate of the emitted greenhouse gases from aviation. The total effect varies with time horizon and altitude. The factor is significantly smaller for short-hauls than for long-distance flights. For a distance of $500 \mathrm{~km}$ it was assumed that the true value falls within the range of factor 1.0-1.5 of the radiative forcing of the $\mathrm{CO}_{2}$ emitted with 1.3 as a central value.

\subsubsection{Traffic scenarios}

In this analysis, the simulated emissions per passenger kilometer are applied to five different scenarios. Each scenario gives one example of how traffic generated by the investment in a new high speed line may be divided percentagewise on diverted traffic from other modes of transport, generated new traffic and pre-existing train passengers. Table 2 shows the assumptions made concerning how traffic is divided into the five scenarios. 
Table 2: Share of traffic on a new high speed link divided on sub-categories for the scenarios (per cent of total traffic).

\begin{tabular}{|l|l|l|l|l|l|}
\hline & \multicolumn{3}{|l|}{$\begin{array}{l}\text { Traffic diverted from } \\
\text { other modes (per cent) }\end{array}$} & $\begin{array}{l}\text { Generated } \\
\text { new traffic } \\
\text { (per cent) }\end{array}$ & $\begin{array}{l}\text { Pre-existing } \\
\text { train passengers } \\
\text { (per cent) }\end{array}$ \\
\hline & Aviation & Car & Bus & & \\
\hline Central estimate & 20 & 20 & 5 & 25 & 30 \\
\hline $\begin{array}{l}\text { High diversion from } \\
\text { aviation }\end{array}$ & 32 & 14 & 4 & 25 & 25 \\
\hline $\begin{array}{l}\text { High diversion from cars } \\
\text { and buses }\end{array}$ & 12 & 32 & 6 & 25 & 25 \\
\hline $\begin{array}{l}\text { High share of new } \\
\text { generated traffic }\end{array}$ & 18 & 18 & 4 & 40 & 20 \\
\hline $\begin{array}{l}\text { High share of pre-existing } \\
\text { train passengers }\end{array}$ & 18 & 18 & 4 & 20 & 40 \\
\hline
\end{tabular}

\section{Resulting emission per million one-way trips}

For each scenario the simulated distributions for the resulting change in emissions per million $500 \mathrm{~km}$ one-way trips is calculated. The distributions are shown in Figure 1.
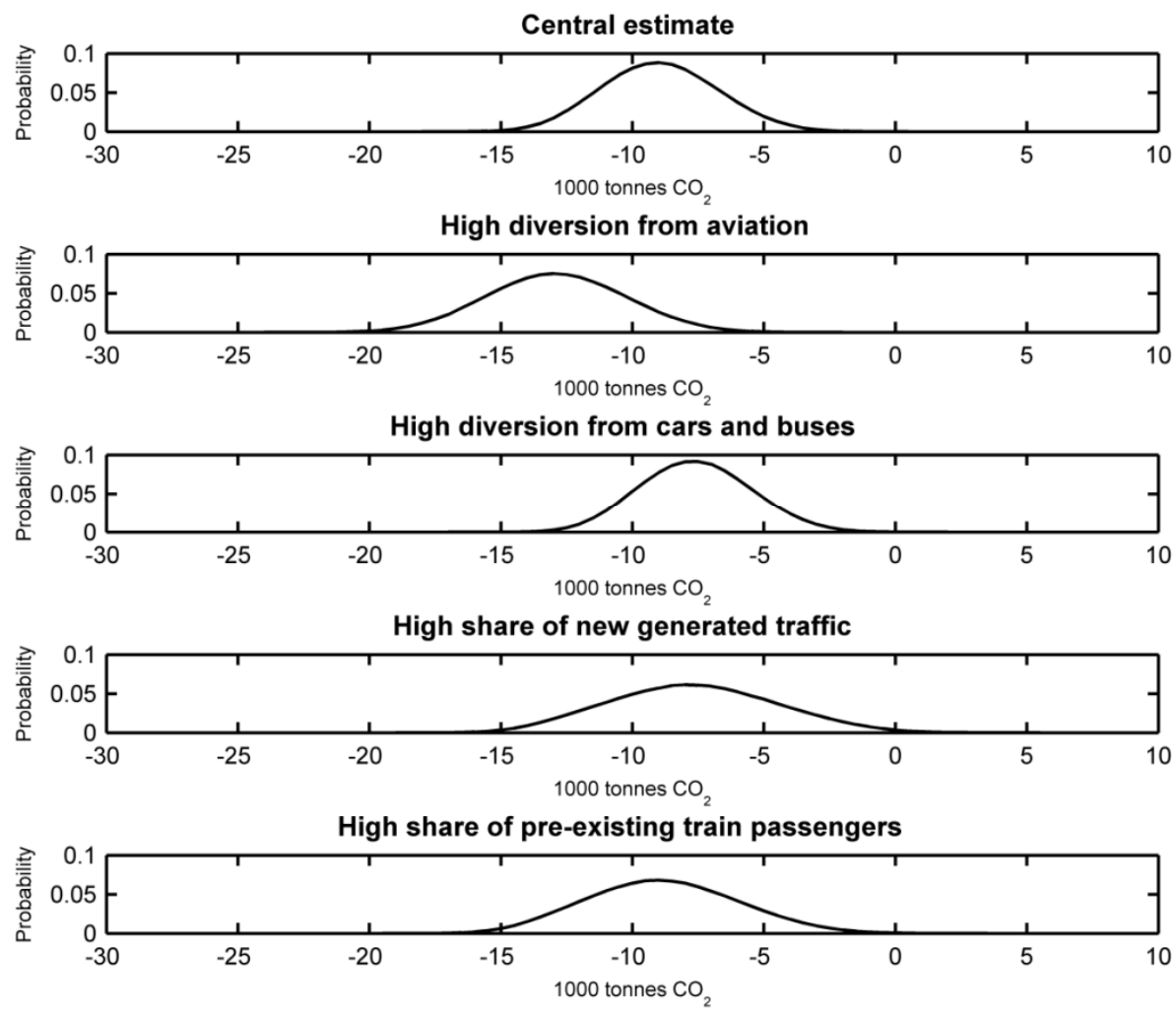

Figure 1: Simulated distributions of the change in emissions per million $500 \mathrm{~km}$ trips for the five different traffic scenarios.

From the figure it can be seen that on average all scenarios reduce total $\mathrm{CO}_{2}$ emissions. The effect is strongest with a high diversion from aviation. However, if the share of newly generated traffic is high, in combination with high emissions from marginal electricity production, there is a small risk that total $\mathrm{CO}_{2}$ emissions will increase instead of decrease. This highlights the importance of evaluating the share of newly generated traffic when estimating the environmental impact of investment in transport infrastructure. If the new line 
generates a large number of new trips, which would otherwise not take place, at least from a $\mathrm{CO}_{2}$ reduction perspective, the project may be unfavorable.

\section{Annual traffic required for offsetting embedded emissions}

Large $\mathrm{CO}_{2}$ emissions are generated from the construction and maintenance of a high speed link. In Network Rail (2009) the embedded greenhouse emissions from a high speed link are analyzed. Since the lifespan differs for different elements, the embedded emissions are annualized over the anticipated lifetime of each element. To calculate the embedded emissions there was also a need to consider the whole lifecycle including maintenance and the degree of material recycling when repairing the infrastructure. The embedded emissions are therefore expressed as $\mathrm{CO}_{2}$ equivalent emissions per rail-track km per year.

An important factor for the size of the embedded emissions is the proportion of tunnels versus open sections. Network Rail (2009) assume that the embedded emissions, for open sections, varies between 140 and 230 tonnes $\mathrm{CO}_{2}$ eq. per rail-track km per year depending on the type of track and recycling rate. For tunnel sections the embedded emissions varies between 880 and 980 tonnes $\mathrm{CO}_{2}$ eq. per rail-track km per year. Other studies on the embedded emissions from railway infrastructure come to somewhat different results depending on what factors they include in the analysis and what assumptions they make regarding the design, geographical location and depreciation period of the project (Claro, 2010, and UIC, 2009). The overall magnitude of the embedded emissions is however the same.

To study the overall effect on $\mathrm{CO}_{2}$ emissions from building a new high speed line, a reference project was used. The project is a $500 \mathrm{~km}$ long double track high speed line. Figures for the embedded emissions from the construction are taken from the central estimate in Network Rail (2009) with a recycling rate of 50 per cent and assuming that 10 per cent of the total line is tunnels. The estimated annualized embedded emissions from constructing a $500 \mathrm{~km}$ long double track line is 118,000 tonnes of $\mathrm{CO}_{2}$-eq.

Using the reference project, the required number of trips needed to compensate for the embedded emissions could be calculated. The simulated distribution of the required number of trips is shown in Figure 2. 


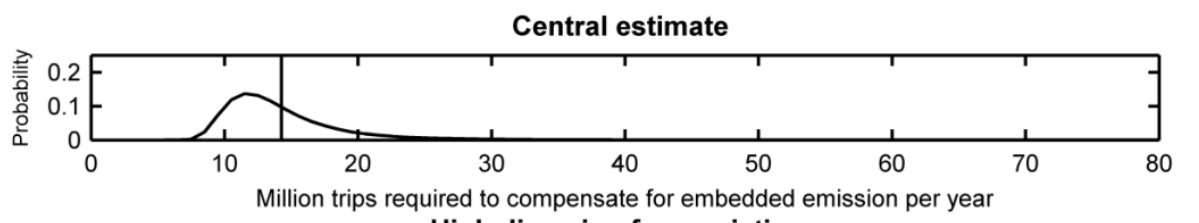

High diversion from aviation

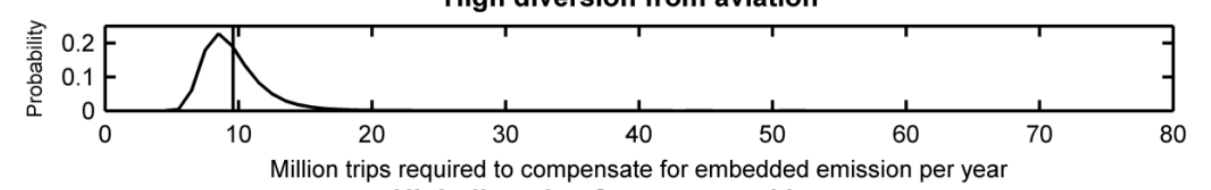

High diversion from cars and buses

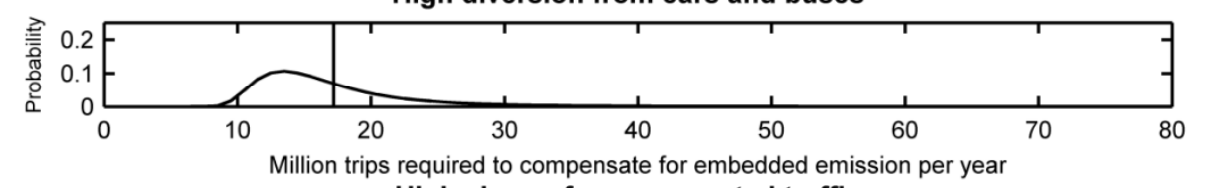

High share of new generated traffic

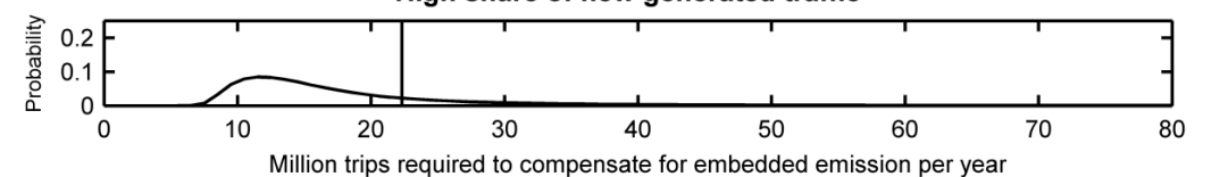

High share of pre-existing train passengers

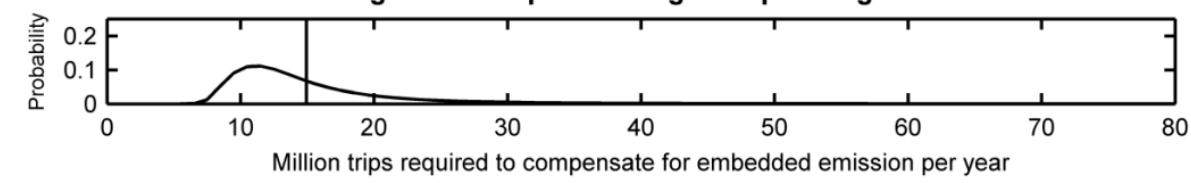

Figure 2: Simulated distributions of the number of annual trips needed to fully compensate for the annualized embedded emissions from constructing and operating the high speed line in the reference project. The mean of the distribution is indicated with a vertical line.

The figure shows how many annual trips are needed to compensate for the embedded emissions from constructing and operating the new high speed line, that is, when the emissions reduction, from the induced modal shift, is equal to the embedded emissions from constructing and operating the railway. When comparing the emissions reduction with the embedded emissions from constructing the new railway, the overall positive result in Figure 1 changes. If the number of annual trips is below the required value, the reduced emissions from traffic diversion cannot compensate for the annualized embedded emissions from the construction. Even with a high diversion from aviation, on average nearly 10 million annual one-way trips are required to compensate for the annualized construction emissions - as indicated by the vertical line in the figure. For the other scenarios, the average number of required annual trips is even higher, between 15 and 20 million.

In this analysis, the reference project consists of a relatively low proportion of tunnels. For a railway with a higher proportion of tunnels, even more trips would be required in order to compensate for the annual embedded emissions of the construction of the project.

\section{Discussion}

\subsection{Discounting greenhouse gas emissions}

In traditional cost-benefit analysis, future costs and benefits would be calculated year-by-year and discounted into net-present value. As one cannot forecast future technological development post 2025 with any degree of accuracy, assumptions were made concerning the nature of new technologies entering the market in 2025 as a proxy for average specific emissions caused during the entire depreciation period. This makes discounting difficult. 
However, a drawback of not discounting is that one cannot distinguish between early and late emissions. By refraining from discounting the value of future benefits, this paper overestimates the net present value of investing in a shift to a low-emitting transport mode.

\subsection{Aspects not covered}

The method used in this paper does not capture all aspects of its subject. As already mentioned, the indirect effect on emissions of greenhouse gases from being able to use existing rail infrastructure for new types of traffic, after opening a new high speed line, is not covered. This aspect is analyzed in Åkerman (2011). However, to be able to make up for any sizeable carbon deficit of a new high speed line that does not attract enough traffic, the indirect climate benefits of making new use of the existing line would have to be significant. If so, it may be better to focus on how to accommodate those types of railway services rather than investing in a new line dedicated to high speed passenger transport.

Another aspect not considered is the possibility that, in the absence of investment in high speed lines, growing demand for rail services would require investment in other kinds of additional capacity where construction would also affect climate change. However, there may also exist other types of response to a growing imbalance between supply and demand that give rise to fewer emissions, e.g. congestion charges and incentives to improve the utilization of inland waterway and/or short sea shipping routes, and the partial replacement of business travel by telecommunication.

A different type of partial coverage is the fact that part of the high speed rail infrastructure, in particular tunnels, may have a lifespan substantially longer than 50 years. Thus, limiting the analysis to a depreciation period of 50 years may be unfair. On the other hand, the benefits of emissions reductions in the distant future may turn out to be much less important than those that take place in the near future, as the world is getting closer and closer to the point where the accumulated concentration of greenhouse gases in the atmosphere will exceed the point where it leads to an increase of the mean average temperature of more than $2{ }^{\circ} \mathrm{C}$.

\subsection{Robustness of the results}

In the Monte Carlo simulation all random parameters were assumed to be uncorrelated. This simplified the specification of the model as there was no need to define a correlation matrix between the parameters. However, the theoretical foundation for this simplification can be questioned since it, for instance, implies that the future emissions per seat kilometer for conventional and high speed trains are uncorrelated, although being based on similar technologies. To verify the results, the robustness of the model with respect to assumptions regarding the parameter correlation structure has been tested.

This was done by identifying groups of parameters that were likely to be correlated. The simulation was repeated based on the assumption that parameters belonging to the same group were perfectly correlated with each other, but uncorrelated with all parameters outside of the group. The correlation decreased the variance of the distributions for emissions per passenger kilometer slightly. However, this only had a small effect on the number of annual trips needed to balance the annualized embedded emissions from the construction of the infrastructure (the mean of the distributions changed with less than five per cent for all traffic diversion scenarios). Since the results did not significantly differ from the results when all parameters were assumed to be uncorrelated, this indicated that the results were robust to changes in the parameter correlation structure. 
Another aspect is that the cap of the European Emissions Trading Scheme (EU ETS) may be seen as guaranteeing that $\mathrm{CO}_{2}$ emissions from power production will not be affected by any increase in demand for electricity. If so, this is equally true for aviation emissions that will become subject to the EU ETS in 2012. Viewed this way, a shift from aviation to trains following investment in high speed rail would, by definition, have zero impact on the overall emission of greenhouse gases. On the other hand, a growing demand for electricity will affect the price of emissions allowances, which may make EU governments hesitant about requiring ambitious future cuts in emissions (WWF, 2009).

\section{Conclusions}

Being able to balance the emissions caused by the construction of a high speed line typically depends on the following four factors:

- the amount of emissions caused by construction and maintenance of the infrastructure;

- the net climate benefit per diverted passenger kilometer;

- the total volume of traffic; and

- the magnitude of the indirect opportunity to reduce emissions by making use of the newly released capacity available on existing parallel lines.

To be able to balance the annualized emissions from the construction of the line, traffic volumes need to be large, and the diverted traffic should primarily come from aviation. The possibility to reduce overall emissions by making new use of the part of the capacity of an existing line, which becomes available as a result of the opening of a high speed link, is sitespecific and depends on future demand for additional rail traffic.

High traffic volumes, thus, appear to be the only way both to recover costs and balance construction emissions. According to the European Commission (2008) -

"Only under exceptional circumstances (a combination of low construction costs plus high time savings) could a new HSR line be justified with a level of patronage below 6 million passengers per annum in the opening year; with typical construction costs and time savings, $a$ minimum of 9 million passengers per annum is likely to be needed".

The Monte Carlo simulation shows that in most cases, traffic volumes of more than 10 million annual one-way trips are required to offset the $\mathrm{CO}_{2}$ emissions from the construction of the high speed line.

An important aspect that was disregarded in the above calculations is the time-lag between construction and the years when its emissions will gradually be paid back. Even if emissions from the construction are balanced in the longer term by reduced emissions from traffic, they do have a short-term impact on the atmospheric concentration of greenhouse gases. There is thus an obvious risk that investing in high speed rail will add to the difficulties of keeping the atmospheric content of greenhouse gases at a level that prevents the mean global temperature from exceeding its pre-industrial level by more than 2 degrees Celsius.

A final conclusion may therefore be that there is cause to consider whether the objectives of new transport infrastructure, being it rail or road, can be reached by measures that imply using fewer resources. For exactly this reason the Swedish government requires the four stage principle to be applied in the assessment of all proposed new infrastructure projects (Swedish 
Ministry of Enterprise, Energy and Communications, 2010). The Swedish Transport Administration must carry out its assessment in the following four steps:

1. Measures that affect transport needs and choice of transport mode.

2. Measures leading to more efficient utilization of existing network.

3. Minor investment in road or track improvement.

4. Major investment in new capacity.

From a climate point of view it may be better to upgrade existing lines and to try to make people substitute air travel by modern telecommunications, rather than investing huge amounts of resources enabling people to travel faster and more often.

\section{References}

Åkerman, 2011. The role of high-speed rail in mitigating climate change - The Swedish case Europabanan from a life cycle perspective. Transportation Research Part D: Transport and Environment, Volume 16, Issue 3, May 2011, Pages 208-217.

Claro, 2010. Towards low-carbon transportation infrastructures. FAL Bulletin, Issue 286, November 2010.

de Rus, G., Nash, C., 2007. In what circumstances is investment in High Speed Rail worthwhile? ITS Working Paper 590, Institute for Transport Studies University of Leeds. http://www.eprints.whiterose.ac.uk/2559/.

de Rus, G., 2008. The Economic Effects of High Speed Rail Investment. OECD/ITF Discussion Papers 2008/16, OECD, International Transport Forum.

EEA, 2009. Environmental impacts and impact on the electricity market of a large-scale introduction of electric cars in Europe. European Environmental Agency, Copenhagen.

ENTSOE, 2010. Ten-year network Development plan 2010-2020. Draft for consultation, European Network of Transmission System Operators for Electricity, Brussels.

European Commission, 2008. Guide to Cost-Benefit Analysis of Investment Projects. Directorate General Regional Policy, European Commission, Brussels. http://ec.europa.eu/regional_policy/sources/docgener/guides/cost/guide2008_en.pdf.

Golombek, R., Greaker, M., Kittelsen, S., Rogeberg, O., Aune, F.R., 2011. Carbon Capture and Storage Technologies in the European Power Market. Energy Journal, Vol. 32. No. 3.

Hacker, F., Harthan, R., Matthes, F., Zimmer, W., 2009. Environmental impacts and impact on the electricity market of a large scale introduction of electric cars in Europe. ETC/ACC Technical Paper 2009/4, European Environmental Agency (EEA).

IEA, 2009, World Energy Outlook 2009. International Energy Agency, Paris. 
Kampman, B., Leguijt, C., Bennink, D., Wielders, L., Rijkee, X., de Buck, A., Braat, W., 2010. Green Power for Electric Cars. Development of policy recommendations to harvest the potential of electric vehicles. CE Delft, Netherlands.

Kågeson, P., 2009. Environmental aspects of inter-city passenger transport. $18^{\text {th }}$ International Transport Research Symposium, Madrid, November 16-18, OECD/ITF Discussion Paper No. 2009/28, OECD, International Transport Forum.

http://www.internationaltransportforum.org/jtrc/DiscussionPapers/DP200928.pdf.

Network Rail, 2009. Comparing environmental impact of conventional and high speed rail. Network Rail, London.

Nilsson, J.E., Pyddoke, R., 2009. Höghastighetsjärnvägar - ett klimatpolitiskt stickspår.

Report to the Expert Group for Environmental Studies 2009:3, Swedish Ministry of Finance, Stockholm.

Sköldberg, H., Unger, T., 2008. Effekter av förändrad elanvändning/elproduktion Modellberäkningar. Elforsk Report 2008:30, Elforsk, Stockholm.

Swedish Ministry of Enterprise, Energy and Communications, 2010. Åtgärdsplanering för transportsystemet 2010-2021. Regeringens skrivelse 2009/10:197, Näringsdepartementet, Stockholm.

Swedish Rail Administration, 2008. Svenska Höghastighetsbanor. Banverket Rapport 200805-30, Banverket, Sweden.

http://www.banverket.se/pages/3646/Svenska höghastighetsbanor.pdf.

UIC, 2008. High speed rail. Fast track to sustainable mobility. International Union of Railways, Paris.

UIC, 2009. Carbon footprint of High-Speed railway infrastructure: Methodology and application of High Speed railway operation of European Railways. International Union of Railways, Paris.

UNIFE, 2008. More rail = Less $\mathrm{CO}_{2}$. The Association of the European Rail Industry, Brussels.

Vessia, Ø., Byskov Lindberg, K., 2008. Vi lavere kraftforbruk i Norge gi lavere $\mathrm{CO}_{2}$-utslipp fra europeisk kraftproduksjon? Published in Kvartalsrapport for kraftmarkedet 1 kvartal 2008, Norges vassdrags- og energidirektorat, Oslo.

WWF, 2009. Auswirkungen von Elektroautos auf den Kraftwerkspark und die $\mathrm{CO}_{2}-$ Emissionen in Deutchland. WWF Deutschland, Frankfurt am Main. 